\title{
LEVANTAMENTO DE RISCOS AMBIENTAIS NA ATIVIDADE DE CONSTRUÇÃO E MONTAGEM DE SISTEMAS ELÉTRICOS NA EXPLORAÇÃO DE PETRÓLEO ON SHORE
}

\author{
Alcimar F. Duarte', Enver F. D. Paiva' e Carlos E. de M. Jerônimo' \\ ${ }^{1}$ Universidade Potiguar (UnP) \\ ${ }^{1}$ alcimar.potiguar@hotmail.com \\ ²enver paiva@hotmail.com \\ 33 enrique@hotmail.com
}

\section{RESUMO}

Neste trabalho foi desenvolvido um levantamento em empresas que prestam serviços de construção e montagem em sistemas elétricos na área de perfuração e exploração de petróleo. 0 estudo foi desenvolvido na região de Mossoró, no Estado do Rio Grande do Norte. O objetivo foi identificar e analisar os agentes físicos a qual os trabalhadores estão expostos, propondo medidas mitigadoras para diminuir as conseqüências danosas, assim como apresentar as boas práticas das empresas, com os investimentos e melhorias no processo produtivo. O estudo consiste na elaboração da matriz de riscos, com uso da ferramenta da análise preliminar de riscos (APR) e posterior análise das instruções normativas e dos modos operatórios originais, desenvolvidos pelos próprios trabalhadores. Também são descritos as fases das tarefas e os riscos físicos associados e sua correlação com os fatores ambientais, constituindo-se num importante elemento para o desenvolvimento de um sistema de prevenção de doenças ocupacionais para todas as empresas que atuam nesse seguimento de distribuição de energia elétrica para empresas exploradoras de petróleo.

Palavras-chave: petróleo, os riscos ambientais, plataforma de perfuração, os mapas de risco.

\section{ABSTRACT}

This work presents a survey of companies that provide construction services and installation in electrical systems in the area of drilling and oil exploration. The study was conducted in the region of Mossoró in the state of Rio Grande do Norte. The objective was to identify and analyze the physical agents to which workers are exposed, proposing mitigation measures to reduce the harmful consequences, as well as presenting the good practices of companies with investments and improvements in the productive process. The study is the development of the risk matrix, using the tool of the preliminary risk analysis (PRA) and subsequent analysis of the regulatory instructions and original methods of operation, developed by the workers themselves. It also describes the phases of the tasks and risks associated physical and its correlation with environmental factors, constituting an important element for the development of a system of prevention of occupational diseases for all companies operating in the following distribution of electricity for petroleum companies.

Key-words: petroleum, environmental risks, drilling rig, the risk maps. 


\section{INTRODUÇÃO}

Responsável por grande parte das modificações e evoluções da sociedade moderna do século $X X$ e $X X I$, o petróleo tem ganhado destaque em todos os ramos produtivo e setores industriais estando presente no cotidiano do homem contemporâneo. Após a sua descoberta e beneficiamento no início do século XX diversos setores ligados a produção de bens de consumo passam a abandonar as outras formas de energia e começam a adotar o petróleo como sua fonte principal (THOMAS, 2001).

Segundo Petrobrás (2012) os meios de transporte se popularizaram de forma exponencial proporcionado por uma fonte de energia mais eficaz, barata e relativamente abundante para os meios produtivos presentes no período de seu surgimento. Diversos outros derivados desse produto passam a ser inventado e reinventado proporcionando facilidades e melhoria na qualidade de vida de todos.

O petróleo nos proporciona muitos benefícios, porém, é grande responsável pelas mudanças climáticas e agravamento da saúde de muitos trabalhadores conforme relata MAPFRE (2009). Com um processo de extração do petróleo, segundo Thomas (2001), divididos em diversas etapas as quais se destacam: a sondagem (através do processo de geofísica), a perfuração, exploração, armazenamento, transporte e refinamento. Esses processos estão subdivididos em micro processos ou atividades derivadas que expõem uma grande massa de trabalhadores a diversos riscos ambientais, onde em virtude de sua complexidade expõem estes a riscos químicos, físicos, ergonômicos, biológicos e riscos de acidente.

Em virtude da amplitude da atividade nos deteremos aos riscos físicos existentes, principais agentes de acidentes na referida atividade. Em especial, a subárea a ser desdobrada no desenvolvimento do presente trabalho consiste na atividade de eletrificação de poços de petróleo, com um foco na busca de respostas para melhorias no processo produtivo, de forma a contribuir com a diminuição da exposição destes profissionais a ambientes insalubres, e proporcionar maior produtividade e melhor qualidade de vida realizando as mesmas atividades laborais.

O estudo desenvolveu-se nos campos de petróleo da região de Mossoró no Estado do Rio Grande do Norte, com empresas responsáveis pela construção de redes de distribuição de energia elétrica de média e baixa tensão responsável por alimentar os motores das unidades de bombeamentos dos poços de exploração de petróleo. Essa região possui características diferenciadas, reunindo áreas litorâneas, urbanas e rurais, assim como tipos de solo e formações rochosas, proporcionando assim, considerável representatividade no que concerne aos ambientes de trabalho, conforme descreve IDEMA (2012).

Em virtude da grande quantidade de trabalhadores dedicados a essa atividade, se faz necessário uma atenção especial voltada ao desenvolvimento de doenças ocupacionais de fatores relacionados a falhas no processo produtivo que venham a expor estes a situações degradantes de calor excessivo, ruídos muito acima do permitido por leis ou vibração por tempo prolongado acima do permitido pela legislação. Diversos fatores podem contribuir para esse cenário, desde máquinas e equipamentos velhos, sem manutenção, a falta do uso de EPC e EPI, assim como pressão psicológica do empregador para exceder o tempo de uso do equipamento para conclusão do serviço ou maior produtividade, conforme relata Amorim (2010).

A prevenção, em relação aos riscos provenientes dos procedimentos técnicos, pode ser melhorada ao longo do tempo, pois os riscos, em sua maioria, são conhecidos e podem ser facilmente mapeados e controlados; e tal princípio é adotado por Brasil (2012). 
As interferências e conseqüências dos fatores relacionados ao meio ambiente, entretanto, não são bem conhecidas e nem divulgadas, principalmente devido ao aspecto localizado e imediatista das análises de acidentes ou doença ocupacional. Em determinadas situações, quando ocorrem acidentes de grandes proporções as atenções se voltam para a questão da prevenção de acidentes, talvez mais pela repercussão e o valor do dano do que, propriamente, pelos operários acidentados. Considera-se, entretanto, que não existe dano maior do que a perda de vidas humanas, fato que ocorre diariamente nos diferentes tipos de atividades profissionais. Em algumas atividades, ditas perigosas, como os serviços em redes de energia elétrica, ainda ocorrem graves acidentes, mesmo contando com padrões preestabelecidos de segurança (MELO et al., 2003).

Machado; Porto \& Freitas (2000) alertam que várias concepções das análises de acidentes tendem a culpar os trabalhadores (as próprias vítimas), limitando o aprendizado das organizações com suas falhas. Principalmente quando se considera que esse tipo de análise limitado é empregado freqüentemente no Brasil, encontrando-se ainda presente em diversas concepções oficiais sobre acidentes de trabalho, como nas normas da Associação Brasileira de Normas Técnicas (ABNT) e na Comunicação de Acidente de Trabalho (CAT) do Instituto Nacional do Seguro Social (INSS), em que há um campo específico para o preenchimento do objeto causador.

Na situação das doenças ocupacionais motivada por ambientes insalubres não é diferente, segundo Aguiar (2011) na maioria dos casos a culpa recai sobre o funcionário que ainda são visto como vilões. Visto que descumprem as normas e orientações da empresa, motivando a aparição de doenças ocupacionais e suas conseqüentes perdas laborais, isso quando não trilham pela concepção de um problema de saúde já existente e não comunicado.

Assim a identificação dos agentes físicos aos quais os colaboradores estão expostos só é viável após levantamento criterioso das fases das tarefas e perigos, para posteriormente, pautado em análises crítica e criteriosa identificar os riscos, os quais estão diretamente ligados ao tipo de processo produtivo e propor as medidas mitigadoras. O ruído, vibração e as temperaturas extremas, conforme alerta Brevigliero et al (2010), estão presentes em inúmeras atividades, principalmente nas indústrias de processamento químico, como refinarias e petroquímicas, na indústria com uso de vasos de pressão, tecelagens, automobilística entre outras.

Nas atividades de eletrificação, os níveis de exposição detectados variam, conforme os fatores: localidade, clima, tipo de solo, estação do ano, tipo de equipamento adotado, estado de conservação das máquinas e equipamentos, uso de EPC ou EPI e diversas outras variáveis e particularidades. Predominantemente, no quesito risco físico os principais perigos associados dizem respeito as derivações do ruído, da vibração e das temperaturas extremas como principais fatores de absenteísmo, ou melhor, ligados a doenças ocupacionais dos trabalhadores. Entre os principais impactos gerados pelos ruídos, na Tabela 1, são apresentados os principais elementos relativos as questões auditivas, não auditivas e efeitos sinérgicos (Pignati; Machado, 2005).

Tabela 1. Efeitos da exposição ao ruído.

\begin{tabular}{|l|l|}
\hline \multicolumn{2}{|c|}{ EFEITO DO RUÍDO } \\
\hline Auditivos & $\begin{array}{l}\text { Deslocamento temporário do limiar auditivo, surdez profissional: condutiva e } \\
\text { neurossensorial }\end{array}$ \\
\hline Não auditivos & $\begin{array}{l}\text { Dor de cabeça, irritabilidade, vertigens, cansaço excessivo, insônia, dor no coração e } \\
\text { zumbido na orelha }\end{array}$ \\
\hline Sinérgicos & Ruído e tolueno \\
\hline
\end{tabular}


A exposição ocupacional sujeita os colaboradores a vibrações de corpo inteiro e localizado (mãos e braços), ocasionando elementos degradantes a saúde conforme descrito, na tabela 2 , sendo lesivo a vida laboral do mesmo (Brevigliero et al, 2010).

Tabela 2. Efeitos da exposição à vibração.

EFEITO DA EXPOSIÇÃO À VIBRAÇÃO

\begin{tabular}{l|l|}
\hline $\begin{array}{l}\text { Exposição a baixa frequência } \\
\text { no corpo inteiro }\end{array}$ & $\begin{array}{l}\text { Dores abdominais, náuseas, dor no peito, perda de equilíbrio, respiração curta e } \\
\text { contrações musculares }\end{array}$ \\
\hline $\begin{array}{l}\text { Exposição de longa duração } \\
\text { no corpo inteiro }\end{array}$ & $\begin{array}{l}\text { Fadiga, irritabilidade, dores de cabeça, distúrbios cardiovasculares e impotência } \\
\text { masculina, desordem da espinha. }\end{array}$ \\
\hline $\begin{array}{l}\text { Exposição de curta duração } \\
\text { no corpo inteiro }\end{array}$ & Aumento dos batimentos cardíacos, estresse e leve hiperventilação. \\
\hline Exposição localizadas & Síndrome de vibração de mãos e braços, síndrome do canal cárpio. \\
\hline
\end{tabular}

As temperaturas extremas são característica da região estudada e a exposição continuada ao sol, junto com a realização de atividades com altas taxas metabólicas são responsáveis por expor os colaboradores aos possíveis efeitos descrito na Tabela 3 (Brevigliero et al, 2010).

Tabela 3. Efeitos da exposição ao ruído.

EFEITOS DE TEMPERATURAS EXTREMAS

\begin{tabular}{|l|l|}
\hline Intermação & Dor de cabeça, vertigem, desmaio e desconforto abdominal. \\
\hline $\begin{array}{l}\text { Insolação, golpe de calor, } \\
\text { choque térmico, prostação } \\
\text { térmica e exaustão do calor }\end{array}$ & Dor de cabeça, tonturas, mal-estar, fraqueza. \\
\hline Cãibras do calor & Contrações musculares dolorosas e violentas \\
\hline Catarata & Dificuldade para enxergar \\
\hline
\end{tabular}

O processo de serviços de eletrificação, na indústria de exploração e produção do petróleo, consiste na montagem de estrutura de cabos de alumínio aéreos fixados em isoladores sob postes que conduzem a energia até a aérea do poço onde proporcionarão o funcionamento de motores, que são responsáveis pela movimentação de equipamentos utilizados para extração do óleo bruto. Este serviço é composto pelas etapas de desmatamento com o uso de máquinas, locação de postes com suporte do georreferenciamento, escavação de buracos, implantação de postes, montagem de estruturas, instalação de transformadores, instalação e a interligação dos quadros elétricos com a rede alimentadora, de média tensão de 13.8 kV; conforme descreve Petrobrás (2012).

$\mathrm{Na}$ etapa de desmatamento, quanto ao risco físico, observa-se a exposição dos funcionários a altas doses de ruído, vibração e calor excessivo. Sendo esta etapa desenvolvida por operadores, que fazem uso de máquinas retroescavadeiras. Esses equipamentos avançam sobre a área a ser desmatada, derrubando a vegetação e planando o solo para que possa ser preparado o acesso para as equipes avançarem com os postes e os equipamentos a serem montados e instalados nos locais desmarcados.

Em etapas anteriores, é desenvolvido pela equipe de topografia, um direcionamento para nivelamento das áreas. Em virtude do desnivelamento do solo e a trepidação do motor os colaboradores estão, constantemente, expostos a vibrações e solavancos; que podem ao longo do tempo proporcionar desde problemas digestivos a sérios problemas locomotores (gerados por lesões na coluna e articulações), que podem diminuir sua capacidade laboral ou até mesmo inviabilizá-lo de trabalhar. 


\section{Rev. Elet. em Gestão, Educação e Tecnologia Ambiental (e-ISSN: 2236-1170)}

Em relação ao agente físico calor, tem-se que é a grande força motriz do desconforto térmico e fadiga, podendo proporcionar desde problemas digestivos, falta de atenção, problemas cardíacos, problemas de pressão, desmaios, diminuição da produção entre outros, conforme descreve Aguiar (2011). Prevalecem aquelas que implicam alta carga radiante sobre o trabalhador, e essa é a parcela freqüentemente dominante na sobrecarga térmica que vem a se instalar; todavia, muitas atividades com carga radiante moderada, porém acompanhadas de altas taxas metabólicas (trabalhos extenuante ao ar livre), também podem oferecer sobrecargas inadequadas. Em suma, deve-se tomar cuidado em não tipificar categoricamente as situações ocupacionais quanto ao calor; o melhor é analisar criteriosamente cada uma delas.

Por todas as atividades prevalecer às condições ambientais com exposição aos agentes físicos já descritos, variando apenas em intensidade conforme particularidades da fase da tarefa e condições climáticas.

Diante desse quadro, o presente trabalho visa apresentar um critério de levantamento de perigos associados a tais atividades, com o enquadramento numa metodologia de Análise Preliminar de Riscos (APR), para tipificar e priorizar os diferentes agentes e suas conseqüências. A partir dessa matriz de priorização serão estabelecidas recomendações a serem implementadas na aplicação de Programas de Prevenção a Riscos Ambientais, de empresas prestadoras desse tipo de atividade. Auxiliando na atenuação dos riscos físicos e no levantamento de informações técnicas de segurança do trabalho nessa atividade.

\section{METODOLOGIA}

\section{1. Área de Estudo}

A área utilizada para o levantamento dos dados encontra-se localizada na região do município de Mossoró, RN, cuja atividade principal é exploração e produção do petróleo. A localização é ilustrada na Figura 1.

$\mathrm{Na}$ ocasião da visita em Junho de 2012, foram realizados levantamentos junto aos trabalhadores de empresas prestadoras de serviços de instalações elétricas, observando sua atuação e conversando sempre que fosse possível.

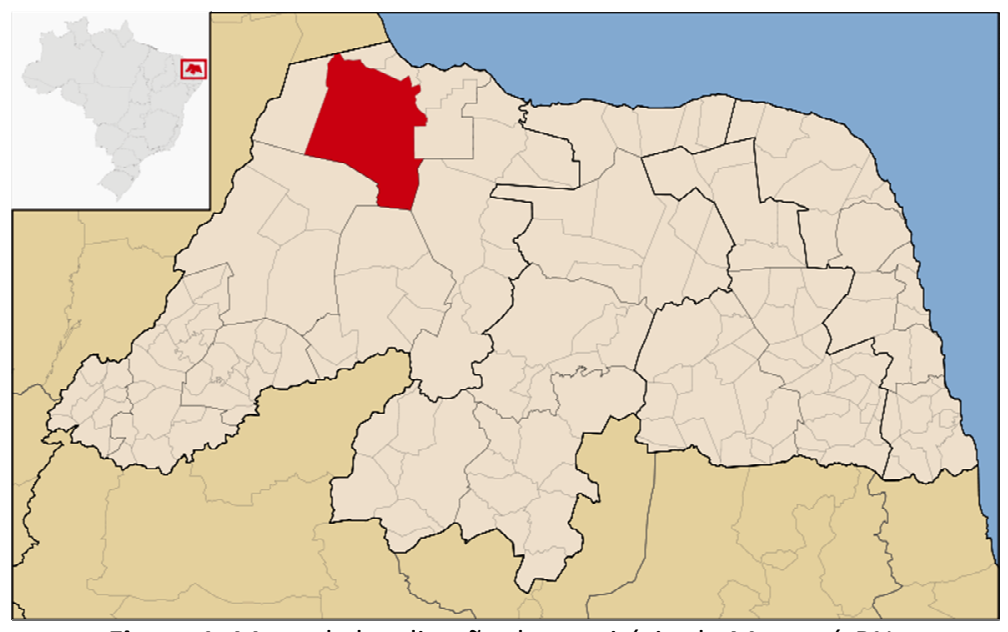

Figura 1. Mapa de localização do município de Mossoró-RN. 
Fonte: Wikipédia (2012).

\subsection{Levantamento de Dados}

O estudo constitui-se de uma pesquisa aplicada, pois objetiva produzir conhecimentos em segurança e saúde no trabalho para aplicação no ramo da montagem de sistemas elétricos para empresas de exploração e produção de petróleo.

Do ponto de vista dos objetivos, trata-se de um estudo exploratório-descritivo, o qual visa descrever a problemática em discussão, buscando caracterizar o objeto de estudo.

O trabalho consiste em avaliar os riscos físicos e, devido à importância, os riscos ergonômicos nos serviços de construção e montagem, bem como, propor medidas adequadas que contribuam para a melhoria da segurança e saúde de seus trabalhadores.

Do ponto de vista dos procedimentos técnicos, o estudo caracteriza-se como pesquisa bibliográfica, por sua elaboração a partir do levantamento e análise de material já publicado, em artigos científicos, livros, relatórios técnicos, etc. (SILVA; MENEZES, 2001), e como estudo de caso devido a utilização de dados de campo.

A estrutura da pesquisa consiste em: formulação do problema, englobando a justificativa do estudo; a determinação dos objetivos; a contextualização da problemática e definição da metodologia; realização do levantamento teórico, que orienta a caracterização do objeto de estudo; as definições e conceitos a serem utilizados em análise e correntes de pensamentos que norteiam a hipótese da pesquisa; levantamento de dados em campo e a discussão sobre as melhorias que possam acarretar.

Os dados coletados, em campo, foram organizados e utilizados para elaboração da Planilha de Análise Preliminar de Riscos (APR).

Esse estudo foi realizado com base num levantamento exploratório qualitativo que possibilitou descrever e analisar os riscos físicos e ergonômicos. Os dados foram coletados e analisados utilizando-se como técnicas de trabalho em campo e de interpretação das informações coletadas, respectivamente, a observação e a análise preliminar de riscos físicos.

\subsection{Análise de Risco}

A metodologia da APR compreende a execução das seguintes etapas: definição dos objetivos e do propósito da análise; definição das fronteiras do processo analisado; levantamento de campo para coleta de informações sobre a instalação e os perigos envolvidos; subdivisão do processo em etapas; realização da APR propriamente dita (preenchimento da planilha); caracterização dos cenários identificados através de uma matriz de classificação de risco (freqüência e severidade) e análise dos resultados (AGUIAR, 2011).

A partir do que foi observado durante o trabalho de campo, foi elaborada uma classificação dos riscos encontrados no local.

Após a coleta e organização dos dados aplicou-se a metodologia para classificação dos riscos que se baseia na Análise Preliminar dos Riscos-APR correspondente a etapa de identificação, descrição e classificação dos riscos associados ao cenário de trabalho.

Foram determinadas as classes de freqüências, nível de deficiência, nível de exposição, nível de probabilidade, nível de severidade e nível de risco, a metodologia foi baseada no estudo de Camacho (2005) e Pedro (2007), com adaptações na seqüência de ações e enquadramento. 
Para determinação da classe de freqüência dos riscos (CFR) utilizou-se uma escala onde as notas variam de 0 a 3, conforme a classe de freqüência do risco: 0 - freqüência remota; 1 - pouco provável; 2- provável e 3 - freqüente $(\geq 1)$.

O nível por nível de deficiência (ND), ou nível de ausência de medidas preventivas, a magnitude esperada entre o conjunto de fatores de risco considerados e a sua relação causal direta com o acidente. A Tabela 1, que se segue, define o enquadramento da avaliação do cenário num determinado nível de deficiência.

Tabela 1. Nível de Deficiência (ND) para os cenários estudados

\begin{tabular}{|c|c|c|}
\hline Nível de Deficiência & ND & Significado \\
\hline Aceitável (A) & 1 & Não foram detectadas anomalias. O perigo está controlado. \\
\hline Insuficiente (I) & 2 & $\begin{array}{l}\text { Foram detectados fatores de risco de menor importância. É de admitir que o dano } \\
\text { possa ocorrer algumas vezes. }\end{array}$ \\
\hline Deficiente (D) & 6 & $\begin{array}{c}\text { Foram detectados alguns fatores de risco significativos. O conjunto de medidas } \\
\text { preventivas existentes tem a sua eficácia reduzida de forma significativa }\end{array}$ \\
\hline Muito Deficiente (MD) & 10 & $\begin{array}{l}\text { Foram detectados fatores de risco significativos. As medidas preventivas existentes } \\
\text { são ineficazes. O dano ocorrerá na maior parte das circunstâncias. }\end{array}$ \\
\hline Deficiência Total (DT) & 14 & $\begin{array}{c}\text { Medidas preventivas inexistentes ou inadequadas. São esperados danos na maior } \\
\text { parte das situações. }\end{array}$ \\
\hline
\end{tabular}

Para o nível de exposição pode ser estimado em função dos tempos de permanência nas áreas de trabalho, operações com a máquina, procedimentos, ambientes de trabalho, etc., conforme Tabela 2.

Tabela 2. Nível de Exposição (NE) para os cenários estudados

\begin{tabular}{|c|c|c|}
\hline Nível de Exposição & NE & Significado \\
\hline Esporádica & 1 & Uma vez por ano ou menos e por pouco tempo (minutos) \\
\hline Pouco Freqüente & 2 & Algumas vezes por ano e por período de tempo determinado \\
\hline Ocasional & 3 & Algumas vezes por mês \\
\hline Freqüente & 4 & $\begin{array}{c}\text { Várias vezes durante o período laboral, ainda que com tempos curtos - } \\
\text { várias vezes por semana ou diário }\end{array}$ \\
\hline $\begin{array}{c}\text { Continuada } \\
\text { Rotina }\end{array}$ & 5 & Várias vezes por dia com tempo prolongado ou continuamente. \\
\hline
\end{tabular}

O nível de probabilidade foi obtido através das medidas preventivas existentes e do nível de exposição ao risco. Pode ser expresso num produto de ambos os termos apresentado na Tabela 3 abaixo. 


\section{Rev. Elet. em Gestão, Educação e Tecnologia Ambiental (e-ISSN: 2236-1170)}

Tabela 3. Probabilidade dos Riscos

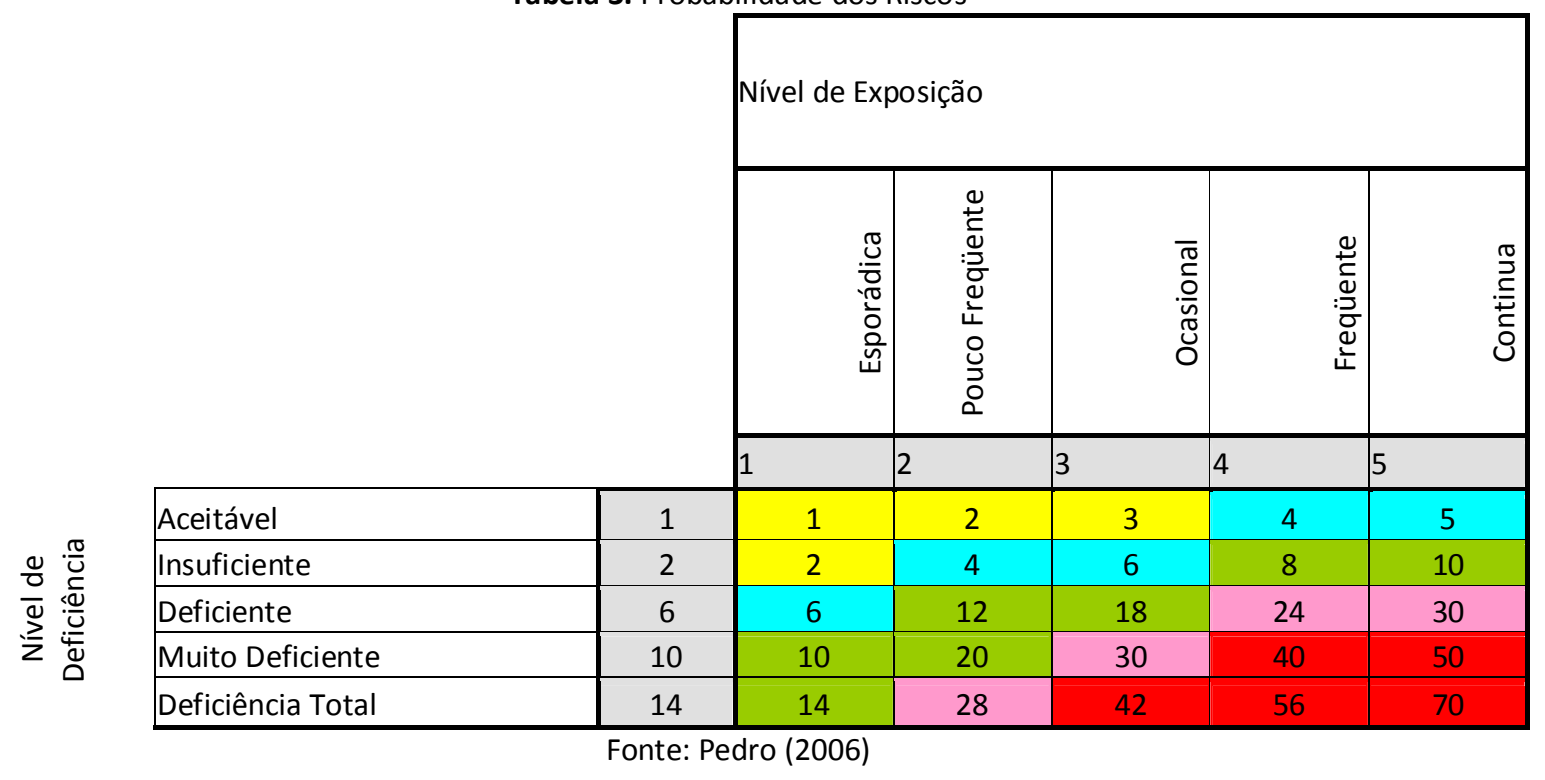

Foram considerados cinco níveis de conseqüências em que se categorizaram os danos físicos causados as pessoas e os danos materiais. Ambas as categorias devem ser consideradas independentemente, tendo sempre mais peso os danos nas pessoas que os danos materiais. Quando os danos em pessoas forem desprezíveis ou inexistentes devemos considerar os danos materiais no estabelecimento das prioridades, conforme Tabela 4.

Tabela 4. Nível de Probabilidade (NP) para os cenários estudados

\begin{tabular}{ccc}
\hline $\begin{array}{c}\text { Nível de } \\
\text { Probabilidade }\end{array}$ & NP & Significado \\
\hline Muito Baixa & {$[1 ; 3]$} & Não é de esperar que a situação perigosa se materialize, ainda que possa ser \\
concebida
\end{tabular}


DUARTE et al., v(7), no 7, p. 1449-1460, MAR-AGO, 2012.

Rev. Elet. em Gestão, Educação e Tecnologia Ambiental (e-ISSN: 2236-1170)

Tabela 5. Nível de Severidade (NS) para os cenários estudados

\begin{tabular}{|c|c|c|c|}
\hline \multirow{2}{*}{ Níveis de Severidade } & \multirow{2}{*}{ NS } & \multicolumn{2}{|c|}{ Significado } \\
\hline & & Danos Pessoais & Danos Materiais \\
\hline Insignificante & 10 & Não há danos pessoais & Pequenas perdas materiais \\
\hline Leve & 25 & $\begin{array}{l}\text { Pequenas lesões que não requerem } \\
\text { hospitalização. Apenas primeiros } \\
\text { socorros }\end{array}$ & Reparação sem paragem do processo \\
\hline Moderado & 60 & $\begin{array}{c}\text { Lesões com incapacidade laboral } \\
\text { transitória. Requer tratamento } \\
\text { médico }\end{array}$ & $\begin{array}{l}\text { Requer a paragem do processo para } \\
\text { efectuar a reparação }\end{array}$ \\
\hline Grave & 90 & $\begin{array}{l}\text { Lesões graves que podem ser } \\
\text { irreparáveis. }\end{array}$ & $\begin{array}{c}\text { Destruição parcial do sistema (reparação } \\
\text { complexa e onerosa) }\end{array}$ \\
\hline Mortal ou catastrófico & 155 & $\begin{array}{l}\text { Um morto ou mais. } \\
\text { Incapacidade total ou permanente }\end{array}$ & $\begin{array}{l}\text { Destruição de um ou mais sistemas } \\
\text { (difícil renovação / reparação) }\end{array}$ \\
\hline
\end{tabular}

Fonte: Pedro (2007)

Para o nível de risco foi elaborado através do resultado do produto do nível de probabilidade pelo nível das consequências NR=NPxNS, e que pode apresentar-se na Figura 2, seguinte:

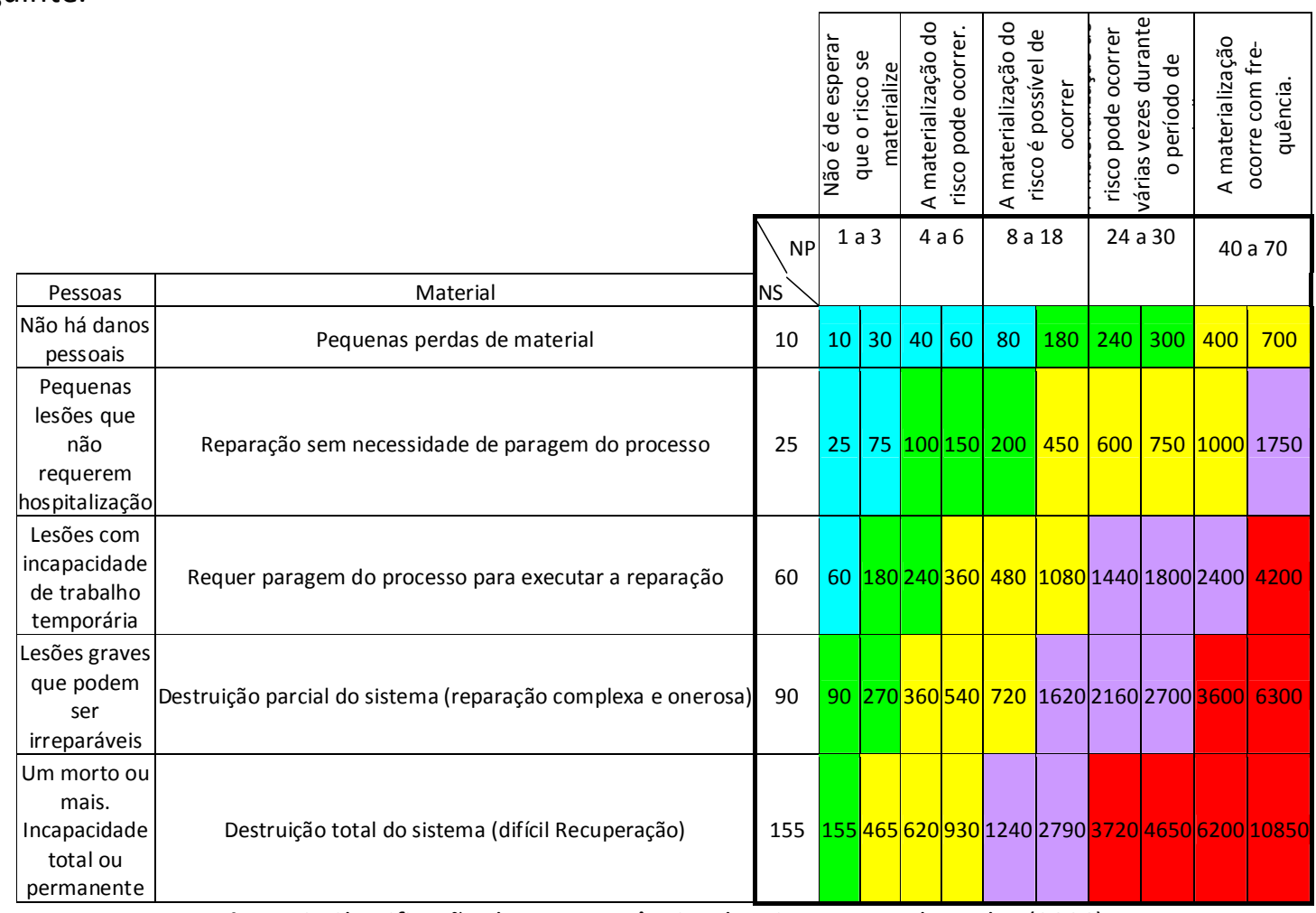

Figura 2. Classificação das consequências dos riscos segundo Pedro (2006).

Com os riscos identificados, o passo seguinte é a construção do mapa de riscos físicos da atividade, com a priorização de cenários, e adotar medidas conforme orientações da Tabela 6.

Tabela 6. Nível de Riscos (NR) para os cenários estudados 
Rev. Elet. em Gestão, Educação e Tecnologia Ambiental (e-ISSN: 2236-1170)

\begin{tabular}{|c|c|c|}
\hline \multirow{2}{*}{ Níveis de Criticidade } & \multirow{2}{*}{ NC } & Significado \\
\hline & & Danos Pessoais \\
\hline $\mathrm{I}$ & $\begin{array}{l}3600 \text { a } \\
10850\end{array}$ & $\begin{array}{l}\text { Situação Critica. Intervenção Imediata. Eventual paralisação dos serviços e } \\
\text { Isolamento do perigo. }\end{array}$ \\
\hline II & $\begin{array}{c}1240 \text { a } \\
3100\end{array}$ & $\begin{array}{l}\text { Situação a corrigir. Adotar medidas de controle enquanto a situação ao for } \\
\text { eliminada ou reduzida. }\end{array}$ \\
\hline III & 360 a 1080 & $\begin{array}{c}\text { Situação requer melhorias e deverão ser elaborados programas ou } \\
\text { procedimentos para auxiliar na intervenção }\end{array}$ \\
\hline IV & 90 a 300 & Melhorar se possível a intervenção \\
\hline $\mathrm{V}$ & 10 a 80 & Intervir apenas se uma análise estratégica e mais aprofundada justificar. \\
\hline
\end{tabular}

\section{RESULTADOS E DISCUSSÕES}

Foram visitados e analisadas diversas frentes de serviço nas quais pode-se observar que embora haja presença de um ambiente insalubre proporcionado pelas atividades realizadas a céu aberto, expondo os trabalhadores a altas temperaturas e exposição continuada a raios solares de forma freqüente, assim como nos processos mecanizados a presença de ruído excessivo e vibrações prejudiciais a saúde dos mesmos, também foi viável encontrar iniciativas que tem diminuído o risco de doenças ocupacionais.

É notório a necessidade da substituição de máquinas retroescavadeiras de modelos antigos por modelos mais modernos, providos de cabine acústica, ar refrigerado e cadeira com sistema de absorção de vibração.

Os caminhões utilizados no processo de eletrificação aos poucos já se ver uma substituição por modelos mais modernos e confortáveis com equipamentos mais seguros e que exige menor esforço físico nas operações, ainda existem diversas empresas que fazem uso de compressor com marteletes pneumáticos para serviço de escavação em solo com presença de rocha.

Porém, já existem iniciativas que substitui o martelete pneumático por marteles hidráulicos acoplados as retroescavadeiras com as características de conforto descritas anteriormente, esta iniciativa auxilia a saúde dos funcionários de forma significativa visto que a proteção acústica da cabine da máquina, a cadeira com absorção de vibração, o ar condicionado do equipamento que proporciona temperatura agradável, as pausas para descanso e o uso de protetor auricular tem sido excelentes ferramentas para o aumento da produtividade e a redução da taxa de abstenseísmo.

É bem verdade que ainda se faz necessário um esforço significativo por parte das empresas para eliminação total dos ambientes insalubres, visto que, ainda é fator determinante no processo de altos valores necessários a ser investido em modernização de máquinas, desenvolvimento de pesquisas e em métodos de produção que privilegie a mecanização dos serviços insalubres.

É preciso que trabalhadores e empresários pensem em conjunto formas de produções que minimizem a exposição dos colaboradores a cenários insalubres e maximizem soluções para uma produção lucrativa, sustentável e dignificante aqueles que trabalham.

\section{CONCLUSÕES}




\section{Rev. Elet. em Gestão, Educação e Tecnologia Ambiental (e-ISSN: 2236-1170)}

Desta forma, se conclui que, as atividades de eletrificações desenvolvidas pelos empregados das empresas contratadas expõem estes na maioria dos casos a condições ambientes acima do limite de tolerância, abrindo precedente a percepção do adicional de insalubridade e debilidade na saúde do trabalhador, os quais podem serem eliminados se medidas de controle forem implantadas de maneira a garantir condições menos agressiva a saúde dos colaboradores.

A comprovação da guarda, conservação, uso efetivo, higienização e treinamento da utilização adequada dos EPC's e EPI's, assim como o controle da entrega aos empregados e a realização de campanhas de monitoramentos de agentes físicos, são ações eficazes capazes de promover além do prolongamento da vida laboral do trabalhador, uma melhor qualidade de vida e um aumento da produtividade e conseqüente lucratividade da empresa.

São necessários investimentos em maquinários, novas tecnologias e um maior comprometimento com a figura humana que proporcionarão uma sociedade que passa a lucrar pautada em uma consciência de contribuição firmada não apenas no crescimento individual, mas sim no desenvolvimento coletivo com menos custos para o INSS, sistema de saúde e um ganho significativo para colaborador e família.

\section{REFERÊNCIAS BIBLIOGRÁFICAS}

1. AGUIAR, L. A. Metodologias de Análise de Riscos - APP \& Hazop. Rio de Janeiro: 2011. Disponível em: <http://professor.ucg.br/SiteDocente/admin/arquivosUploa/materia.pdf>. Acesso em: 06 jul. 2012.

2. AMORIM, E. L. C. de. Ferramentas de Análise de Risco. Apostila do curso de Engenharia Ambiental da Universidade Federal de Alagoas, CTEC, Alagoas: 2010. Disponível em: < http://pt.scribd.com/doc/71505557/Apostila-de-ferramentas-de-analise-de-risco>. Acesso em: 08 jul. 2012.

3. BRASIL, Normas Regulamentadoras do Ministério do Trabalho e Emprego. Disponível em: <http://portal.mte.gov.br/legislacao/normas-regulamentadoras-1.htm>. Acesso em: 08 Jul. 2012.

4. BREVIGLIERO, E. J. P. et al. Higiene Ocupacional: Agentes Biológicos, Químicos e Físicos. 5․ São Paulo: SENAC, 2010.

5. CAMACHO, E. N. Uma Proposta de Metodologia para Análise Quantitativa de Riscos Ambientais. (2004). Tese - Programa de Pós-graduação de Engenharia, Universidade Federal do Rio de Janeiro, 2004.

6. CETESB. Manual de orientação para elaboração de estudos de análise de riscos. 2000.

7. IDEMA. Mossoró. Disponível em: http://www.idema.rn.gov.br. Acesso em: 15/07/2012.

8. MACHADO, J. M. H.; PORTO, M. F. S.; FREITAS, C. M. Perspectivas para uma análise interdisciplinar e participativa de acidentes (AIPA) no contexto da indústria de Processo, pp. 49-81. Fiocruz, Rio de Janeiro. 2000.

9. MAPFRE. Mudanças climáticas e analise de risco da industrial de petróleo no litoral brasileiro. Instituto de Ciências del Seguro. Madrid. 2009.

10. MELO, L. A. et al. "Segurança nos serviços emergenciais em redes elétricas: os fatores ambientais." Revista Produção, 2003.

11. PEDRO, R. Métodos de Avaliação e Identificação de Riscos nos Locais de Trabalho. Revista Tecnometal. n. $\cong 167$ de Nov/Dez 2006. 


\section{REGETAUFSM}

DUARTE et al., v(7), no 7, p. 1449-1460, MAR-AGO, 2012.

\section{Rev. Elet. em Gestão, Educação e Tecnologia Ambiental (e-ISSN: 2236-1170)}

12. PEDRO, R. Métodos de Avaliação e Identificação de Riscos nos Locais de Trabalho. Revista KÉRAMICA. n. 286 de Setembro/Outubro, 2007.

13. PETROBRAS. Serviços de Exploração e Produção. Disponível em: http://www.petrobras.com.br. Acesso em: 16/07/2012.

14. PIGNATI, W. A.; MACHADO, J. M. H. Riscos e agravos à saúde e à vida dos trabalhadores das indústrias madeireiras de Mato Grosso. Ciênc. saúde coletiva, Rio de Janeiro, v. 10, n. 4, Dec. 2005. 15. SILVA, E. L.; MENEZES, E. M. Metodologia da pesquisa e elaboração de dissertação. 3 ed. Rev. Atual. Florianópolis: Laboratório de Ensino à Distância da UFSC, 2001.

16. THOMAS, J. E. Fundamentos de Engenharia de Petróleo. Petrobras. Rio de. Janeiro: Interciência, 2001.

17. WIKIPEDIA. Mossoró. Disponível em: http://pt.wikipedia.org/wiki/Mossoro. Acesso em: $15 / 07 / 2012$. 